\title{
Características morfológicas do pelame de vacas holandesas puras por cruza na região semiárida de Minas Gerais
}

\author{
[Hair coat characteristics of graded Holstein cows in semiarid region of \\ Minas Gerais State, Brazil] \\ B.C. Mata e Silva, A.C. Almeida*, L.C.G. Marques, B.R. Porto, C.R.S. Durães, \\ I.S. Carvalho Júnior, F. Colen \\ Universidade Federal de Minas Gerais. Instituto de Ciências Agrárias - ICA - Montes, Claros, MG
}

\section{RESUMO}

O objetivo do trabalho foi avaliar as características morfológicas como densidade numérica e espessura do pelame e comprimento dos pelos de vacas Holandesas predominantemente negras, puras por cruza em lactação na região de Montes Claros no norte de Minas Gerais. O estudo foi conduzido em duas fases, A: julho/agosto e B: outubro/novembro de 2010, utilizando 12 fêmeas Holandesas em lactação, puras por cruza de pelame predominante negro. Foram medidas as características de densidade numérica $\left(\mathrm{n}^{\mathrm{O}}\right.$ pelos $\left./ \mathrm{cm}^{2}\right)$, espessura $(\mathrm{mm})$, comprimento $(\mathrm{mm})$ e a temperatura da superfície do pelame (TPE). Os resultados mostraram que o pelame foi menos denso, com pelos mais curtos na fase $\mathrm{B}$, no entanto a espessura não variou entre as duas fases. No período em que ocorreu maior densidade numérica houve menor TPE. As características do pelame das vacas Holandesas puras por cruza observadas indicam uma boa adequação às condições ambientais da região em estudo.

Palavras-chave: bovino, comprimento, densidade, espessura, pelo, estação do ano

\begin{abstract}
The aim of this work was to evaluate the morphological characteristics such as number density, coat thickness and length of predominantly black lactating graded Holstein cows, in the region of Montes Claros in the north of Minas Gerais. The study was conducted in two phases, A: July/August and B: October/November 2010, using 12 lactating female Holstein crossbred dairy cows with predominant black coat. We measured the characteristics of numerical density (number of hair/ $\mathrm{cm}^{2}$ ), thickness ( $\mathrm{mm}$ ) length ( $\mathrm{mm})$ and coat surface temperature (CST). Three samples of hair of each animal were taken at each stage through adjusted pliers. The results showed that the coat was less dense, with shorter hair in phase B, and the thickness did not change in the two phases. In the period when the coat was denser, that is, phase A, there was lower CTS. The observed coat characteristics of graded Holstein cows indicate good adaptation to environmental conditions in the region.
\end{abstract}

Keywords: bovine, density, hair coat, length, season, thickness

\section{INTRODUÇÃO}

A termorregulação é um dos processos vitais executados pela pele. Esta tem funções térmicas variadas incluindo as de gerar, absorver, transmitir, radiar, vaporizar e conduzir calor $(\mathrm{Xu}$ et al., 2008). O papel termorregulador do pelame pode ser dividido em dois processos: proteção contra o aumento da absorção da radiação solar e a dissipação do excesso de calor da superfície animal, pois a perda de calor por evaporação em bovinos ocorre principalmente na epiderme, respondendo por, aproximadamente, $80 \%$ da perda total (Ligeiro et al., 2006). A cor do pelame e suas características (espessura, número de fibras por área, diâmetro e comprimento do pelo) podem afetar consideravelmente os mecanismos de troca térmica (Pocay, et al., 2001).

Recebido em 9 de julho de 2012

Aceito em 17 de julho de 2013

* Autor para correspondência (corresponding author)

E-mail: aca2006@ica.ufmg.br 
Queda na produção de leite de $20-30 \%$ foi observada em animais criados em ambientes com alta temperatura e umidade relativa. $\mathrm{O}$ organismo do bovino sob estresse térmico necessita liberar grandes quantidades de calor metabólico para prevenir o superaquecimento e elevação da temperatura corporal em valores que poderiam comprometer a saúde (Gebremedhin e Wu, 2002).

Pesquisas publicadas envolvendo a morfologia do pelame e bem estar animal foram conduzidas dentro de ambientes controlados em câmaras climáticas em regiões e climas temperados e subtropicais (Silva et al., 2011). Dados de regiões semiáridas são escassos, principalmente aqueles conduzidos com animais leiteiros, puros por cruza ou mestiços.

Objetivou-se avaliar as características morfológicas como densidade numérica e espessura do pelame e comprimento do pelo de vacas Holandesas em lactação, predominantemente negras, puras por cruza, na região semiárida de Minas Gerais.

\section{MATERIAL E MÉTODOS}

A pesquisa foi conduzida no setor de bovinocultura de leite na Fazenda Experimental Hamilton de Abreu Navarro no Instituto de Ciências Agrárias da Universidade Federal de Minas Gerais (FEHAN-ICA/UFMG), localizada no município de Montes Claros, região norte de Minas Gerais. Segundo a classificação de Köppen, o clima predominante na região é o Aw - tropical de savana, possuindo duas estações bem definidas, havendo registros de deficiência hídrica nos meses de maio a outubro, com temperatura média anual acima de $24,2^{\circ} \mathrm{C}$, sendo a mínima de $14,8^{\circ} \mathrm{C}$ e a máxima acima de $31^{\circ} \mathrm{C}$ com índice pluviométrico médio anual de 1.200 mm (Köppen, 1948 citado por Nogueira et al., 2009).

As coletas de dados foram realizadas no ano de 2010 com avaliação em dois períodos distintos, caracterizando, duas fases experimentais, sendo, A: julho/agosto e a B: outubro/novembro, com uma coleta de pelos em cada fase. Foram utilizadas em cada período 12 vacas Holandesas em lactação, de pelame negro, pluríparas, puras por cruza, provenientes de cruzamentos absorventes na FEHAN-ICA/UFMG. Os animais foram selecionados de acordo com a produção de leite e dias de lactação mantendo homogeneidade no lote, nas duas fases observadas. O delineamento experimental utilizado foi $o$ inteiramente ao acaso, com 12 repetições (animais) em duas épocas distintas (tratamentos).

As características morfológicas do pelame como espessura, comprimento e densidade foram determinadas conforme os métodos descritos por Silva (2000). A espessura do pelame foi realizada com emprego de paquímetro em três locais do corpo do animal, abaixo da linha dorsal, na região torácica mediana.

Três amostras de pelo foram coletadas utilizando-se alicate adaptado para este fim. A densidade foi calculada, contando-se o número de pelos da amostra na área conhecida do alicate $\left(0,16 \mathrm{~cm}^{2}\right)$ e transformando os valores em número de pelos por $\mathrm{cm}^{2}$. Para o cálculo do comprimento médio dos pelos, foi tomada a média aritmética dos dez maiores pelos da amostra, eleitos por análise visual e medidos com paquímetro. A temperatura do pelame (TPE) foi aferida por meio de termômetro infravermelho digital, portátil e realizada a média ponderada de acordo com Souza (2003).

Foi instalado globo negro confeccionado de acordo com Souza et al. (2002) e sistema de aquisição de dados (datalogger) na parte externa da instalação utilizando um abrigo meteorológico para coleta da temperatura ambiente (TBS) e umidade relativa do ar (UR) e índice de temperatura do globo e umidade (ITGU). O ITGU foi realizado de acordo com Buffington $e t$ al. (1981).

Os dados foram submetidos ao teste de Cochran (homocedasticidade) e de Lilliefors (normalidade de dados). Nos dados em que essas premissas não foram atendidas, como em densidade e comprimento, foram transformados em logaritmo neperiano (ln $\mathrm{x})$, em seguida submetidos à análise de variância a $5 \%$ de probabilidade pelo programa SAEG versão 9.1, 2007 e, logo após retransformados para o valor real.

\section{RESULTADOS E DISCUSSÃO}

Os valores médios das características do pelame estão apresentados na Tab. 1 . 
Tabela. 1. Média, desvio padrão, mínimo, máximo e coeficiente de variação (CV) das características do pelame: densidade dos pelos (DN), espessura do pelame (EP), comprimento dos pelos (CP) e temperatura da superfície do pelame (TPE), medidas em vacas Holandesas puras por cruza em Montes Claros no norte de Minas Gerais.

\begin{tabular}{|c|c|c|c|c|c|}
\hline \multirow[b]{2}{*}{ Fase } & \multirow[b]{2}{*}{ Parâmetros } & \multicolumn{3}{|c|}{ Variáveis } & \multirow[b]{2}{*}{$\begin{array}{l}\text { TPE } \\
\left({ }^{\circ} \mathrm{C}\right) \\
\end{array}$} \\
\hline & & $\begin{array}{c}\text { DN } \\
\left(\mathrm{n}^{\mathrm{o}} \text { de pelos } / \mathrm{cm}^{2}\right)\end{array}$ & $\begin{array}{c}\mathrm{EP} \\
(\mathrm{mm})\end{array}$ & $\begin{array}{c}\mathrm{CP} \\
(\mathrm{mm})\end{array}$ & \\
\hline \multirow{3}{*}{ A } & Média e desvio padrão & $953 \pm 401$ & $2,8 \pm 1,1$ & $11,7 \pm 4,6$ & $30,8 \pm 0,85$ \\
\hline & Mínimo & 360 & 1 & 4,1 & 29,3 \\
\hline & Máximo & 1529 & 5,3 & 19,9 & 32,4 \\
\hline \multirow{6}{*}{ B } & Média e desvio padrão & $477 \pm 113$ & $3,1 \pm 0,6$ & $8,0 \pm 1,9$ & $34,3 \pm 0,86$ \\
\hline & Mínimo & 315 & 2,1 & 5,5 & 32,8 \\
\hline & Máximo & 737 & 4,2 & 11,2 & 35,8 \\
\hline & Média das fases & 715 & 2,9 & 9,8 & 32,5 \\
\hline & $\mathrm{CV}(\%)$ & 6,1 & 30,3 & 15,3 & 2,53 \\
\hline & $p$ & 0.00094 & ns & 0.02428 & 0.00000 \\
\hline
\end{tabular}

A média da densidade do pelame nas duas fases foi de 715 pelos $/ \mathrm{cm}^{2}$ sendo semelhante aos relatados por outros autores em animais da raça Holandesa: 707 pelos $/ \mathrm{cm}^{2}$ (Pinheiro e Silva, 2000) e 718 pelos $/ \mathrm{cm}^{2}$ (Bianchini et al., 2006). Observou-se que a densidade dos pelos na fase A $\left(953 \mathrm{pelos} / \mathrm{cm}^{2}\right.$ ) foi o dobro daquela registrada para a fase B (477 pelos $\left./ \mathrm{cm}^{2}\right)$. Esses resultados indicam que no período primavera/verão poderia haver mais folículos pilosos vazios que no outono/inverno, isto é, os pelames foram menos densos na primavera, época mais quente, e mais densos no inverno, época mais fria (Tab. 2).

Tabela 2. Média, desvio padrão, mínimo, máximo e coeficiente de variação $(\mathrm{CV})$ da temperatura ambiente (TBS), umidade relativa do ar (UR) e índice de temperatura do globo e umidade durante as duas fases experimentais em vacas Holandesas puras por cruza em Montes Claros no norte de Minas Gerais.

\begin{tabular}{llccc}
\hline \multirow{2}{*}{ Fase } & \multirow{2}{*}{ Parâmetros } & \multicolumn{3}{c}{ Variáveis } \\
\cline { 3 - 5 } & & TBS $\left({ }^{\circ} \mathrm{C}\right)$ & UR $(\%)$ & ITGU \\
\hline \multirow{2}{*}{ Média e desvio padrão } & $23,8 \pm 1,4$ & $50 \pm 4,8$ & $75 \pm 1,5$ \\
& Mínimo & 21,5 & 41 & 72 \\
B & Máximo & 26,1 & 58 & 78 \\
& Média e desvio padrão & $29,0 \pm 1,9$ & $53 \pm 11,1$ & $82 \pm 2,5$ \\
$p$ & Mínimo & 24,7 & 33 & 77 \\
$\mathrm{CV}(\%)$ & Máximo & 32 & 80 & 86 \\
\hline
\end{tabular}

$\mathrm{p}<0,05$, ns. não significativo

Morais (2002) estudou a influência da época do ano sobre as características do pelame de vacas da raça Holandesa e observou altas densidades no outono e inverno, sendo semelhante ao encontrado no presente estudo. $\mathrm{O}$ autor relatou que esse resultado de menor densidade pode ser devido a alguma muda de pelame, comum de ocorrer em regiões subtropicais.

Façanha et al. (2010), encontraram média geral de 1552 pelos $/ \mathrm{cm}^{2}$ valor bastante superior à registrada por pesquisas brasileiras, incluindo os resultados obtidos no presente estudo e por Maia et al. (2003) que verificaram em pelame negro densidade de 932 pelos $/ \mathrm{cm}^{2}$ e Bertipaglia et al. (2005) que encontraram o valor de 1004 pelos $/ \mathrm{cm}^{2}$. Bianchini et al. (2006) mediante análise de animais naturalizados brasileiros, visualizaram que quanto menor o número de pelos por unidade de área, mais facilmente o vento penetra na capa de pelos e remove o ar aprisionado, o que favorece a transferência térmica. 
Pelames menos densos, com pelos mais curtos e assentados (Tab. 1) ocorreram na época em que se registrou maior valor de temperatura radiante observada por meio do ITGU (Tab. 2). A desvantagem adaptativa desse comportamento é que este tipo de pelame apresenta menor resistência ao fluxo de calor latente e sensível por meio da capa. Isso pode promover superaquecimento do organismo ou até mesmo predispor o animal a lesões cutâneas, sobretudo se a epiderme abaixo desse tipo de pelame for despigmentada (Façanha et al., 2010).

Gray et al. (2011) evidenciaram que vacas com pelos densos em ambientes quente e úmido apresentaram maior risco de estresse térmico e desidratação como observado em regiões de climas subtropicais nos Estados Unidos.

$\mathrm{O}$ período em que o pelame foi mais denso ocorreu na fase de menor TPE (Tab. 1). Pelame menos denso possui uma estrutura física mais aberta e, portanto, susceptível a maior penetração da radiação ultravioleta (Silva et al., 2001). Porém, no presente estudo os animais eram predominantemente de pelame escuro, e em animais Holandeses a pigmentação da epiderme acompanha a do pelame, tendo assim uma maior proteção pela pele pigmentada. A maior carga de calor recebida do ambiente, em função da cor escura do pelame pode ter sido eliminada via termólise convectiva, em função da menor densidade, comprimento dos pelos e espessura da capa do pelame (Azevedo et al., 2005). Silva e Maia (2011) avaliaram dezesseis vacas puras de origem quanto à evaporação e a TPE às 13h, após 6 horas de exposição ao sol, no mesmo local (flanco, pescoço e glúteo) e considerando separadamente as malhas negras e as brancas. Nas áreas negras a taxa de sudação, a taxa de termólise por evaporação cutânea e a TPE foram maiores que nas áreas brancas. Os autores concluíram que em animais Holandeses a temperatura da pele em áreas escuras foi significativamente maior que em áreas brancas, em um mesmo animal, quando exposto ao sol.

Trabalhos citados por Silva et al. (2011) evidenciaram a importância da pigmentação para as trocas térmicas radiantes nos animais. As radiações de ondas curtas são transmitidas no interior da capa e esta é mais acentuada nas capas de coloração clara que nas escuras. Quanto a absorvidade para radiação térmica, as epidermes de coloração escura oferecem proteção eficaz contra radiação ultravioleta em relação a epidermes claras ou despigmentadas.

Com relação à espessura do pelame, a média obtida nas duas fases foi de $2,9 \mathrm{~mm}$. Esse valor pode ser considerado adequado para regiões quentes, onde são desejáveis pelames menos espessos, que facilitam a termólise (Morais, 2002). Esse valor pode ser considerado baixo para vacas Holandesas de acordo com o descrito por Bertipaglia et al. (2005), que encontraram e classificaram os resultados em 2,48mm, espessura baixa, 12,4mm de comprimento, pelos curtos e 1004 pelos $/ \mathrm{cm}^{2}$, baixa densidade, indicando a adaptação das vacas Holandesas ao ambiente quente do estado de São Paulo.

Esses resultados se mostram próximos aos encontrados no presente estudo, para todas as características do pelame, podendo indicar assim a adaptação dos animais Holandeses puras por cruza ao ambiente, pois a espessura, densidade e comprimento do pelo não ultrapassam $8 \mathrm{~mm}$, 1400 pelos $/ \mathrm{cm}^{2}$ e $24 \mathrm{~mm}$, respectivamente, valores estes relatados por Udo et al. (1978) para animais Holandeses criados em regiões temperadas.

Os animais tiveram média do comprimento do pelame de $9,8 \mathrm{~mm}$ durante o estudo. Azevedo et al. (2005) encontraram valores médios de 7,7, 8,9 e 9,2mm para animais Holandês x Zebu, observando que animais com o grau de sangue mais próximo ao zebu obtiveram comprimentos menores. Segundo Silva (2000), esses animais possuem pelo mais curto, sendo uma característica de adaptação dos animais às regiões tropicais, onde há temperaturas mais elevadas, e o pelo curto contribui para a perda de calor.

Castanheira et al. (2010) em estudos com ovinos no Brasil Central concluíram que o comprimento do pelo e a espessura do pelame foram fatores importantes em características raciais para se obter animais mais resistentes e a pigmentação da pele foi necessária para proteger os tecidos contra excesso de exposição à luz solar nas zonas tropicais.

Em vacas de maior grau de sangue Holandês, Maia et al. (2003), verificaram valores de comprimento de pelo de 12,05mm, Façanha et al. 
(2010), 12,18mm e Veríssimo et al. (2006), $10,9 \mathrm{~mm}$, observando que a média geral do presente estudo, foi abaixo do relatado na literatura.

Constatou-se diferença $(\mathrm{p}<0,05)$ no comprimento dos pelos, entre as duas fases, com os animais apresentando pelos mais compridos na fase $\mathrm{A}$ $(11,7 \mathrm{~mm})$ que na fase B $(8,0 \mathrm{~mm})$. Essa diferença pode ter ocorrido uma vez que os bovinos apresentam modificações cíclicas anuais com substituição dos pelos mais longos no inverno por pelos mais curtos no verão. Marai et al. (2007) observaram que o tamanho do pelo é importante característica morfológica para o balanço térmico do corpo. Silva (2000) cita que a cor, espessura, número de glândulas, número de pelos por área, comprimento e ângulo de inserção na pele, são de grande importância, pois permitem ao animal trocar calor com o ambiente por radiação, convecção, evaporação e condução.

As adaptações dos animais às condições ambientais é de grande importância para a resistência ao estresse térmico, sendo evidenciado no presente estudo, pois os animais utilizados eram provenientes de cruzamentos absorventes realizados na fazenda há 13 anos, o que pode ter interferido nos resultados (Tab. 1 e Tab. 2), mediante os relatos da literatura.

As características estruturais do pelame poderiam ser utilizadas para a seleção de animais resistentes ao calor. Em ambientes de alta radiação ultravioleta, a combinação mais adequada seria pelame branco sobre epiderme negra, na impossibilidade deste, prefere-se o pelame de cor negra, pois em nenhuma das situações, a espessura da capa de pelame deve ser maior que 4 a $5 \mathrm{~mm}$ (Silva et al., 2011).

A composição genética do rebanho em relação à característica dos pelos interferem nos mecanismos de respostas ao estresse térmico. Silva et al. (2011), ao estudarem a perda de calor latente em animais cruzados Holandês x Zebu em ambiente semiárido equatorial, relataram melhores resultados em animais com pelos menores que $3 \mathrm{~mm}$. Os autores observaram que tal característica pode ser generalizada entre raças europeias no Brasil, como resultado de um processo de aclimatização, pois, pelos finos são mais favoráveis à perda de calor por convecção e evaporação.
Maia et al. (2003) e Maia et al. (2005) realizaram pesquisas que avaliaram a influência do perfil genético de animais cruzados Holandês $\mathrm{x}$ Zebu e os resultados indicaram que pelame menos denso, com pelos curtos e grossos favorecem as perdas de calor sensível e calor latente. Os autores observaram que o comprimento e espessura do pelo foram importantes para adaptação nos trópicos, com queda na adaptação com aumento no tamanho dos pelos. Pelos pequenos, brilhantes e finos levaram a melhor dissipação de calor.

\section{CONCLUSÃO}

As características do pelame das vacas Holandesas puras por cruza variaram entre as fases estudadas. As maiores médias de comprimento e densidade numérica dos pelos foram verificadas nas épocas de menores temperaturas ambientais. A espessura do pelame não variou nas duas fases estudadas. As características do pelame possuíam uma boa adequação às condições ambientais da região, facilitando a dissipação de calor. O pelame preto pode ter auxiliado na proteção contra a radiação solar e um pelame menos denso, com pelos bem assentados e curtos, favoreceram as perdas de calor por meio da camada de pelos.

\section{AGRADECIMENTOS}

Pesquisa desenvolvida com recursos FAPEMIG Processo $n^{\circ}$ : APQ-02417-10 e bolsas CAPES/ mestrado, IC/FAPEMIG e CNPq/PIBIC.

COMITÊ DE ÉTICA E BIOSSEGURANÇA: Aprovação pelo CETEA/UFMG sob processo $n^{\circ}$. 43/2010.

\section{REFERÊNCIAS}

AZEVEDO, M.; PIRES, M.F.A.; SATURNINO, H.M. et al. Estimativa de Níveis Críticos Superiores do Índice de Temperatura e Umidade para Vacas Leiteiras 1/2, 3/4 e 7/8 Holandês-Zebu em Lactação. Rev. Bras. Zootec., v.34, p.2000-2008, 2005.

BERTIPAGLIA, E.C.A.; SILVA, R.G.; MAIA A.S.C. Fertility and hair coat characteristics of Holstein cows in a tropical environment. Anim. Reprod., v.2, p.187194,2005 
BIANCHINI, E.; MCMANUS, C.; LUCCI, C.M. et al. Características corporais associadas com a adaptação ao calor em bovinos naturalizados brasileiros. Pesq. Agropec. Bras., v.41, p.1443-1448, 2006.

BUFFINGTON, D.E.; COLLAZO-AROCHO, A.; CANTON, G.H. Black globe humidity index (BGHI) as comfort equation for dairy cows. Trans. ASAE, v.24, p.711-714, 1981 .

CASTANHEIRA, M.; PAIVA, S.R.; LOUVANDINI, $\mathrm{H}$. et al. Use of heat tolerance traits in discriminating between groups of sheep in central Brazil. Trop. Anim. Health Pro., v.42, p.1821-1828, 2010.

FAÇANHA, D.A.E.; SILVA, R.G.; MAIA, A.S.C. $e t$ $a l$. Variação anual de características morfológicas e da temperatura de superfície do pelame de vacas da raça Holandesa em ambiente semiárido. Rev. Bras. Zootec. v.39, p.837-844, 2010.

GEBREMEDHIN, K.G.; WU, B. Simulation of sensible and latent heat losses from wet-skin surface and fur layer. J. Therm. Biol., v.27, p.291-297, 2002.

GRAY, K.A.; SMITH, T.; MALTECCA, C. et al. Differences in hair coat shedding and effects on calf wening weight and BCS among Angus dams. Livest. Sci., v.140, p.68-71, 2011.

LIGEIRO, E.C.; MAIA, A.S.C.; SILVA, R.G. et al. Perda de calor por evaporação cutânea associada às características morfológicas do pelame de cabras leiteiras criadas em ambiente tropical. Rev. Bras. Zootec., v.35, p.544-549, 2006.

MAIA, A.S.C.; SILVA, R.G.; BERTIPAGLIA, E.C.A. Características do Pelame de Vacas Holandesas em Ambiente Tropical: Um Estudo Genético e Adaptativo. Rev. Bras. Zootec., v.32, p.843-853, 2003.

MAIA, A.S.C.; SILVA, R.G.; CERÓN, M.; BERTIPAGLIA, E.C.A. Genetic variation of the hair coat properties and the milk yield of Holstein cows managed under shade in a tropical environment. Braz. J. Vet. Res. Anim. Sci., v.42, p.180-187, 2005.

MARAI, I.F.M.; EL-DARAWANY, A.A.; FADIEL, A.; ABDEL-HAFEZ, M.A.M. Physiological traits as affected by heat stress in sheep - A review. Small Ruminant Res., v.71, p.1-12, 2007.

MORAIS, D.A.E.F. Variação de características do pelame, níveis de hormônios tireoideanos e produção de vacas leiteiras em ambiente quente e seco. 2002. 121f. Tese (Doutorado em Zootecnia) - Faculdade de Ciências Agrárias e Veterinárias, Universidade Estadual Paulista, Jaboticabal.
NOGUEIRA, F.A.; ROCHA, F.T.; RIBEIRO, G.C. et $a l$. Variação sazonal da contaminação por helmintos em matrizes ovinas e borregos submetidos a controle integrado e criados em pastagens tropicais. Ciênc. Rural, v.39, p.2544-2549, 2009.

PINHEIRO, M.G.; SILVA, R.G. Estação do ano e características do pelame de vacas da raça Holandesa. Bol. Ind. Anim., v.57, p.99-103, 2000.

POCAY, P.L.B.; POCAY, V.G.; STARLING, J.M.C. et al. Respostas fisiológicas de vacas Holandesas predominantemente brancas e predominantemente negras sob radiação solar direta. Ars Vet., v.17, p.155161,2001

SILVA, R.G.; MAIA, A.S.C. Evaporative cooling and cutaneous surface temperature of Holstein cows in tropical conditions. Rev. Bras. Zootec., v.40, p.11431147, 2011.

SILVA, R.G. (Ed.) Introdução à bioclimatologia animal. São Paulo: Nobel, 2000, 286p.

SILVA, R.G.; LA SCALA JÚNIOR, N.; POCAY, P.L.B. Transmissão de radiação ultravioleta através do pelame e da epiderme de bovinos. Rev. Bras. Zootec., v.30, p.1939-1947, 2001.

SILVA， R.G.; MAIA， A.S.; COSTA， L.L.M.; QUEIROZ, J.P. Latent heat loss of dairy cows in an equatorial semi-arid environment. Int. J. Biomet., v.56, p.927-932, 2011.

SOUZA, C.F.; TINÔCO, I.F.F.; BAÊTA, F.C. Avaliação de materiais alternativos para confecção do termômetro de globo. Cienc. Agrotec., v.26, p.157164, 2002.

SOUZA, S.R.L. Análise do ambiente físico de vacas leiteiras alojadas em sistema de free stall. 2003. 70f. Dissertação (Mestrado em Engenharia Agrícola) Faculdade de Engenharia Agrícola, Universidade Estadual de Campinas, Campinas.

UDO, H.M. Hair coat characteristics in Friesian heifers in the Netherlands and Kenya: experimental data and a review of literature. 1978. 136f. Tese (Doutorado em Ciências Agrárias) - Mededelingen Landbouwhoge school Wageningen, Wageningen.

VERÍSSIMO, C.J.; OTSUK, I.P.; ARCARO, J.R.P.; TITTO, E.A.L. Comprimento do pêlo em vacas Nelore, Holandesas e Pardo-Suíças, em três épocas do ano. Bol. Ind. Anim., v.63, p.193-198, 2006.

XU, F.; LU, T.J.; SEFFEN, K.A. Biothermomechanics of skin tissues. J. Mech. Phys. Solids. v.56, p.1852$1884,2007$. 